\title{
Polypharmacy in bipolar disorder: Present status and future perspectives
}

\author{
Jan Jaracz $^{1 *}$ and Krystyna Jaracz ${ }^{2}$ \\ ${ }^{1}$ Department of Adult Psychiatry, Poznań University of Medical Sciences Poznan, Poland \\ ${ }^{2}$ Department of Neurological and Psychiatric Nursing, Poznan' University of Medical Sciences, Poznan, Poland
}

\begin{abstract}
Polypharmacy in the treatment of bipolar disorder is the rule rather than the exception. This has been documented in numerous studies carried out in many countries. Some studies indicate that polypharmacy may be more effective than monotherapy in the prophylaxis of BD. Considering the complex neurobiological basis of $\mathrm{BD}$ and the ever-better-known mechanisms of action of mood stabilizers (MS) and second-generation antipsychotics (SGA), one can suppose that in the future the neurobiological signature will allow for the administration of drugs that will cover all disturbed underlying processes. This review presents data showing that individualized approach to the prophylactic treatment of bipolar patients based on their specific neurobiological profile and better knowledge on the effects of the use of two or more mood stabilizing drugs may significantly improve the efficacy of the treatment.
\end{abstract}

\section{Introduction}

Bipolar disorder (BD) is a severe and relatively common mental disorder. Disability, cognitive and functional impairment, as well as excess in mortality, particularly by suicide, are common sequelae of this disease [1]. Early hypotheses linked pathogenesis of BD with disturbances of monoamine systems and genes involved in the metabolism of neurotransmitters and receptors [2]. In recent years several new hypotheses regarding the neurobiology of $\mathrm{BD}$ have been formulated namely: mitochondrial dysfunction and energy metabolism, oxidative stress, up-regulation of glutamatergic neurotransmission and disturbances in the immuno-inflammatory system [3-5]. Numerous studies using magnetic resonance imaging, have documented structural changes in the brain in patients with $\mathrm{BD}[6,7]$.

The first agents that have been shown to be effective in the acute treatment of bipolar episodes and in prophylactic treatment were lithium, valproates and carbamazepine. These properties caused these drugs to be called mood stabilizers (MS) [8-10]. A few decades later mood stabilizing effects of second-generation antipsychotics (SGA) (aripiprazole, olanzapine, risperidone, quetiapine, asenapine, and ziprasidone) as well the new generation of antiepileptic drugs (lamotrigine) have been documented. This led to a significant progress the pharmacological treatment of $\mathrm{BD}$.

The mechanism of action of MS is still yet to be clarified. Lithium affects signal transduction, through its inhibition of second messenger enzymes such as inositol monophosphatase (right), by modulation of $\mathrm{G}$ proteins (middle). Valproates and carbamazepine have, inter alia, a regulatory effect on voltage-gated $\mathrm{Na}+$ channels [11]. Other data suggest a positive impact of lithium on neurogenesis, brain remodeling, angiogenesis, mesenchymal stem cells functioning, and inflammation. This influence is mediated by the inhibition of the glycogen synthase kinase-3, a serine/threonine kinase [12]. The growing evidence point that lamotrigine, lithium and valproate have also anti-inflammatory effect but it differs in details $[13,14]$.
The mechanism of action of SGA is related to their agonistic on 5-HT2A/2C, 5-HT1A, 5-HT6 and 5-HT7 and modulation of D2 receptors as well as on the regulation of glutamatergic System impact [15]. More recent studies have shown that these medications have a more profound effect on brain biochemistry. The stimulation of 5-HT1A receptors, the blockade of 5-HT2 receptors and the stimulation of TrkB receptors by brain-derived neurotrophic factor (BDNF) may increase Ser9 phosphorylation of glycogen synthase kinase-3 $\beta$ (GSK-3 $\beta$ ) finally causing neuroprotective and neurogenic effects [16].

The risk of recurrence in bipolar disease is high, therefore the selection of appropriate medications for prophylaxis of relapse is a crucial and sometimes difficult therapeutic decision. Lithium, the oldest mood stabilizing agent but it is still considered the most effective in this class [17]. For that reason, is recommended as first-line monotherapy for the relapse prevention [18]. However, it is fully effective only in one-third of bipolar patients whereas in others the prophylactic effect is not satisfactory [19]. The clinical efficacy of other medications is also limited to prevention of mainly manic (olanzapine, risperidone-long acting injection, and valproate) or depressive episodes (lamotrigine) [18]. Interestingly, all medications recommended for treatment of $\mathrm{BD}$ except lithium were originally developed for the treatment of schizophrenia or epilepsy. It can, therefore, be assumed that the postulated mechanism of their action probably does not precisely cover the underlying neurobiology and pathophysiology of BD.

${ }^{\star}$ Correspondence to: Jan Jaracz, Department of Adult Psychiatry Poznań University of Medical Sciences 60,60-572-Poznan, Poland, E-mail: jjjaracz@ gmail.com

Key words: bipolar disorder, polypharmacy, mood stabilizers, second-generation antipsychotics

Received: December 18, 2018; Accepted: December 21, 2018; Published: December 24, 2018 
The gap between available and "ideal" medications causes that the practice of using two drugs is often encountered. One of the many definitions of polypharmacy states that this is the long-term use of two or more psychiatric medications in the same patient and the other that it refers to use of two or more medication of the same class to treat the same condition [20]. The practice of the simultaneous use of two or more drugs, to treat one disease is common in medicine and arterial hypertension and epilepsy can be examples.

\section{How often is polypharmacy used in BD?}

Results of the Systematic Treatment Enhancement Program for Bipolar Disorder (STEP-BD) study conducted between 1998-2005 showed that patients, who achieved a remission of symptoms were prescribed averagely 2.05 medications. Lithium (37.1\%) Valproate (34.4\%) and atypical antipsychotics (33.2\%) were the most commonly prescribed medications [21]. Moreover, this study showed that $40 \%$ of subjects used 3 or more drugs, while $18 \%$ received 4 or more agents [22]. The analysis of medical records of bipolar I patients admitted at Butler Hospital in Providence, during the 2010 calendar year found that patients took an average of $3.31(\mathrm{SD}=1.46)$ psychotropic medications at the time of hospitalization. Moreover, 36\% reported taking complex polypharmacy defined as concomitant use of $\geq 4$ psychotropic medications [23]. Data from a large European multicenter study (AMSP) showed that from 1994 to 2009, 85\% of all BP patients received more than one class of psychotropic medications [24]. A more recent report demonstrated that $69 \%$ of BP patients were treated with antipsychotics (AP) and $30.4 \%$ of them received AP polypharmacy. Furthermore $85.5 \%$ of those who were on AP polypharmacy also received MS and/or antidepressant. In turn, $76.9 \%$ of bipolar patients who were on one AP, received concomitant treatment with MS and/or antidepressant [25]. A significant increase of use of SGA was observed between 1998 (18\%) and 2009 (49\%) in the United States. Inversely, in the same period the proportion of patients treated with MS decreased from $82 \%$ to $67 \%$ [26]. During a 2-year Australian prospective, non-interventional, observational study of 239 outpatients with the diagnosis of bipolar I or schizoaffective disorder participants took a median of 5 different psychotropic medications. The application of polypharmacy was associated with some improvement in clinical and functional outcomes [27]. Results of these studies confirm that polypharmacy is used in the majority of bipolar patients.

Treatment guidelines published in recent years recommend monotherapy, preferably with lithium, and augmentation with valproates or SGA if lithium is ineffective [6,14-17]. Except for patients with rapid cycling BD where complex treatment is recommended [19,28-31].

\section{Is polypharmacy more effective than monotherapy in the prophylactic treatment of bipolar patients?}

Results of randomized, placebo-controlled trials suggest that the combination of mood stabilizer and SGA seems more effective than monotherapy in the treatment of acute mania in comparison to monotherapy $[32,33]$.

We have the increasing number of evidence indicating that that polypharmacy may be more effective than monotherapy in the prophylactic treatment of BD. The Balance study demonstrated that during 2-years follow up, combination therapy with lithium plus valproate more effectively prevents relapses in BP I patients than monotherapy with valproates but not lithium [34]. However, in the conclusions the authors state that the results of this study could neither confirm nor refute a benefit of combination therapy compared with lithium monotherapy.
Results of the naturalistic, prospective study conducted by Peselow. et al. [35] showed that patients diagnosed with BP I after acute manic episode were more likely to remain in remission during the two-year follow-up when they took two or more drugs in comparison to those who were on monotherapy. In another study of BP I patients followed for one year after hospitalization due to a manic episode, a combination of atypical antipsychotic and mood stabilizers appeared to be more effective in comparison to monotherapy with mood stabilizers in preventing rehospitalization [36].

A recently published meta-analysis of 15 randomized clinical trials confirmed that participants who received prophylactic treatment with the combination of mood stabilizer and SGA experienced fewer recurrences than those on monotherapy. In contrast to other SGA, only adjunctive treatment with quetiapine reduced both manic and depressive relapses [37].

\section{The future of polypharmacy in BD}

The aim of the interesting recent study was to assess the effects of the combination of lithium, valproate, quetiapine and lamotrigine on markers of inflammation, bioenergetics mitochondrial function and reactive oxygen species in the culture of neuron-like and lipopolysaccharide-stimulated C8-B4 cells [38]. The researchers have shown that quetiapine alone has a proinflammatory effect, but in combination with lamotrigine, both drugs have the anti-inflammatory effects. Moreover, results of this study suggest that various combinations of these drugs have a regulatory effect on mitochondrial capacity. Also, Leu, et al. [39] found the evidence that due to a different effect of lithium and valproate on inflammatory mechanisms these MS prescribed in polypharmacy may provide a complementary immunomodulatory effect. These data may suggest that the use of two drugs may cause new qualitative effects.

The recent Danish study has given a hope that the assessment of multisystem composite biomarkers including expression levels of 19 candidate genes in peripheral blood, plasma levels of BDNF, NT-3, IL-6 and IL-18, leukocyte counts, and urinary markers of oxidative damage to DNA and RNA may be useful in diagnosing of BP [40]. Moreover, few studies showed that neuroimaging data might also be useful in differential diagnosis of bipolar patients but also in the selection of proper treatment [41,42]. The specific combinations of these biomarkers measured on several biological levels may suggest a new neurobiological basis of affective disorders which clinically may manifest as different psychopathological dimensions and finally these "neurobiological signatures" can be helpful in developing algorithms for choosing the individualized treatment [43].

Therefore, further clinical studies of neurobiological and clinical correlates of treatment response are needed to formulate more detailed recommendations to improve the effective management of $\mathrm{BD}$.

\section{References}

1. Grande I, Berk M, Birmaher B, Vieta E (2016) Bipolar disorder. Lancet 387: 15611572. [Crossref]

2. Craddock N, Sklar P (2013) Genetics of bipolar disorder. Lancet 381: 1654-1662. [Crossref]

3. Kim Y, Santos R, Gage FH, Marchetto MC (2017) Molecular Mechanisms of Bipolar Disorder: Progress Made and Future Challenges. Front Cell Neurosci 11: 30. [Crossref]

4. Goldsmith DR, Rapaport MH, Miller BJ (2016) A meta-analysis of blood cytokine network alterations in psychiatric patients: comparisons between schizophrenia, bipolar disorder and depression. Mol Psychiatry 21: 1696-1709. [Crossref] 
5. Munkholm K, Brauner JV, Kessing LV, Vinberg M (2013) Cytokines in bipolar disorder vs. healthy control subjects: a systematic review and meta-analysis. J Psychiatr Res 47 : 1119-1133. [Crossref]

6. Dusi N, De Carlo V, Delvecchio G, Bellani M, Soares JC, et al. (2019) MRI features of clinical outcome in bipolar disorder: A selected review: Special Section on "Translational and Neuroscience Studies in Affective Disorders". Section Editor, Maria Nobile MD, PhD. This Section of JAD focuses on the relevance of translational and neuroscience studies in providing a better understanding of the neural basis of affective disorders. The main aim is to briefly summaries relevant research findings in clinical neuroscience with particular regards to specific innovative topics in mood and anxiety disorders. J Affect Disord 15: 559-563. [Crossref]

7. Arnone D, Cavanagh J, Gerber D, Lawrie SM, Ebmeier KP, et al. (2009) Magnetic resonance imaging studies in bipolar disorder and schizophrenia: a meta-analysis. $\mathrm{Br} \mathrm{J}$ Psychiatry 195: 194-201. [Crossref]

8. Baastrup PC, Schou M (1967) Lithium as a prophylactic agents. Its effect against recurrent depressions and manic-depressive psychosis. Arch Gen Psychiatry 16: 162172. [Crossref]

9. Lambert PA, Borselli S, Marcou G, Bouchardy M, Cabrol G (1971) [Long-term thymoregulative action of Depamide in manic-depressive psychoses]. Ann Med Psychol (Paris) 2: 442-448. [Crossref]

10. Okuma T, Inanaga K, Otsuki S, Sarai K, Takahashi R, et al. (1981) A preliminary double-blind study on the effi cacy of carbamazepine in prophylaxis of manicdepressive illness. Psychopharmacology (Berlin) 73: 95-96. [Crossref]

11. Stahl S (2013) Essential Psychopharmacology. Basis and Practical Applications. Cambridge University Press. Fourth Edition.

12. Dell'Osso L, Del Grande C, Gesi C, Carmassi C, Musetti L (2016) A new look at an old drug: neuroprotective effects and therapeutic potentials of lithium salts. Neuropsychiatr Dis Treat 12: 1687-1703. [Crossref]

13. Abu-Rish EY, Dahabiyeh LA, Bustanji Y, Mohamed YS, Browning MJ (2018) Effect of lamotrigine on in vivo and in vitro cytokine secretion in murine model of inflammation. J Neuroimmunol 322: 36-45. [Crossref]

14. Leu SJ, Yang YY, Liu HC, Cheng CY, Wu YC, et al. (2017) Valproic Acid and Lithium Meditate Anti-Inflammatory Effects by Differentially Modulating Dendritic Cell Differentiation and Function. J Cell Physiol 232: 1176-1186. [Crossref]

15. Meltzer HY (1991) The mechanism of action of novel antipsychotic drugs. Schizophr Bull 17: 263-287. [Crossref]

16. Kusumi I, Boku S, Takahashi Y (2015) Psychopharmacology of atypical antipsychotic drugs: From the receptor binding profile to neuroprotection and neurogenesis. Psychiatry Clin Neurosci 69: 243-258. [Crossref]

17. Malhi GS, Chengappa KN, Gershon S, Ghaemi SN (2011) Atypical mood stabilizers: a new role for neuroleptics? Bipolar Disord 13: 583-586. [Crossref]

18. Goodwin GM, Haddad PM, Ferrier IN, Aronson JK, Barnes T, et al. (2016) Evidence-based guidelines for treating bipolar disorder: Revised third edition recommendations from the British Association for Psychopharmacology. J Psychopharmacol 30: 495-553. [Crossref]

19. Grof P (1999) Excellent lithium responders: people whose lives have been changed by lithium prophylaxis. In: Birch NJ, Gallicchio VS, Becker RW, editors. Lithium: 50 years of psychopharmacology, new perspectives in biomedical and clinical research. Cheshire (CT): Weidner Publishing Group 36-51.

20. Fornaro M, De Berardis D, Koshy AS, Perna G, Valchera A, et al. (2016) Prevalence and clinical features associated with bipolar disorder polypharmacy: a systematic review. Neuropsychiatr Dis Treat 12: 719-735. [Crossref]

21. Al Jurdi RK, Marangell LB, Petersen NJ, Martinez M, Gyulai L, et al. (2008) Prescription patterns of psychotropic medications in elderly compared with younger participants who achieved a "recovered" status in the systematic treatment enhancement program for bipolar disorder. Am J Geriatr Psychiatry 16: 922-933. [Crossref]

22. Goldberg JF, Brooks JO 3rd, Kurita K, Hoblyn JC, Ghaemi SN, et al. (2009) Depressive illness burden associated with complex polypharmacy in patients with bipolar disorder: findings from the STEP-BD. J Clin Psychiatry 70: 155-162. [Crossref]

23. Weinstock LM, Gaudiano BA, Epstein-Lubow G, Tezanos K, Celis-Dehoyos CE, et al. (2014) Medication burden in bipolar disorder: a chart review of patients at psychiatric hospital admission. Psychiatry Res 216: 24-30. [Crossref]

24. Haeberle A, Greil W, Russmann S, Grohmann R (2012) Mono- and combination drug therapies in hospitalized patients with bipolar depression. Data from the European drug surveillance program AMSP. BMC Psychiatry 12: 153. [Crossref]

25. Degli Esposti L, Sangiorgi D, Mencacci C, Spina E, Pasina C, et al. (2014) Pharmacoutilisation and related costs of drugs used to treat schizophrenia and bipolar disorder in Italy: the IBIS study. BMC Psychiatry 14: 282. [Crossref]
26. Pillarella J, Higashi A, Alexander GC, Conti R (2012) Trends in use of secondgeneration antipsychotics for treatment of bipolar disorder in the United States, 19982009. Psychiatr Serv 63: 83-86. [Crossref]

27. Kulkarni J, Filia S, Berk L, Filia K, Dodd S, et al. (2012) Treatment and outcomes of an Australian cohort of outpatients with bipolar I or schizoaffective disorder over twentyfour months: implications for clinical practice. BMC Psychiatry 12: 228. [Crossref]

28. Yatham LN, Kennedy SH, Parikh SV Schaffer A, Beaulieu S, Alda M, et al. (2103) Canadian Network for Mood and Anxiety Treatments (CANMAT) and International Society for Bipolar Disorders (ISBD) collaborative update of CANMAT guidelines for the management of patients with bipolar disorder: update 2013. Bipolar Disord 15:1-44. [Crossref]

29. Grunze H, Kasper S, Goodwin G, Bowden C, Möller HJ (2004) WFSBP Task Force on Treatment Guidelines for Bipolar Disorders (2004) The World Federation of Societies of Biological Psychiatry (WFSBP) guidelines for the biological treatment of bipolar disorders, part III: maintenance treatment. World J Biol Psychiatry 5: 120-135. [Crossref]

30. National Institute for Health and Care Excellence: Bipolar disorder (update): the management of bipolar disorder in adults, children, and adolescents in primary and secondary care. (Clinical Guideline 185.) 2014. www.nice.org.uk/guidance/CG185/ InformationForPublic.

31. Fountoulakis KN, Grunze H, Vieta E, Young A, Yatham L, et al. (2107) The International College of Neuro-Psychopharmacology (CINP) treatment guidelines for Bipolar disorder in adults (CINP-BD-2017), part 3: The clinical guidelines. Int $J$ Neuropsychopharmacol 20: 180-195. [Crossref]

32. Sachs GS, Grossman F, Ghaemi SN, Okamoto A, Bowden CL (2002) Combination of a mood stabilizer with risperidone or haloperidol for treatment of acute mania: a double-blind, placebo-controlled comparison of efficacy and safety. Am J Psychiatry 159: 1146-1154. [Crossref]

33. Tohen M, Chengappa KN, Suppes T, Zarate CA Jr, Calabrese JR, et al. (2002) A Efficacy of olanzapine in combination with valproate or lithium in the treatment of mania in patients partially nonresponsive to valproate or lithium monotherapy. Arch Gen Psychiatry 59: 62-69. [Crossref]

34. BALANCE investigators and collaborators, Geddes JR, Goodwin GM, Rendell J, Azorin JM, et al. (2010) Lithium plus valproate combination therapy versus monotherapy for relapse prevention in bipolar I disorder (BALANCE): a randomised open-label trial. Lancet 375: 385-395. [Crossref]

35. Peselow ED, Naghdechi L, Pizano D, IsHak WW (2016) Polypharmacy in Maintenance of Bipolar Disorder. Clin Neuropharmacol 39: 132-134. [Crossref]

36. Hochman E, Krivoy A, Schaffer A, Weizman A, Valevski A (2016) Antipsychotic adjunctive therapy to mood stabilizers and 1-year rehospitalization rates in bipolar disorder: A cohort study. Bipolar Disord 18: 684-691. [Crossref]

37. Lindström L, Lindström E, Nilsson M, Höistad M (2107) Maintenance therapy with second-generation antipsychotics for bipolar disorder - A systematic review and metaanalysis. J Affect Disord 213: 138-150. [Crossref]

38. Bortolasci CC, Spolding B, Callaly E, Martin S, Panizzutti B, et al. (2018) Mechanisms Underpinning the Polypharmacy Effects of Medications in Psychiatry. Int $J$ Neuropsychopharmacol 21: 582-591. [Crossref]

39. Leu SJ, Yang YY, Liu HC, Cheng CY, Wu YC, et al. (2017) Valproic Acid and Lithium Meditate Anti-Inflammatory Effects by Differentially Modulating Dendritic Cell Differentiation and Function. J Cell Physiol 232: 1176-1186. [Crossref]

40. Munkholm K, Vinberg M, Pedersen BK, Poulsen HE, Ekstrøm CT, et al. (2018) A multisystem composite biomarker as a preliminary diagnostic test in bipolar disorder. Acta Psychiatr Scand. [Crossref]

41. Versace A, Almeida JR, Quevedo K, Thompson WK, Terwilliger RA, et al. (2010) Right orbitofrontal corticolimbic and left corticocortical white matter connectivity differentiate bipolar and unipolar depression. Biol Psychiatry 68: 560-567. [Crossref]

42. Macritchie KA, Lloyd AJ, Bastin ME, Vasudev K, Gallagher P, et al. (2010) White matter microstructural abnormalities in euthymic bipolar disorder. Br J Psychiatry 196 52-58. [Crossref]

43. Phillips ML, Kupfer DJ (2013) Bipolar disorder diagnosis: challenges and future directions. Lancet 381: 1663-71. [Crossref]

Copyright: (C2018 Jaracz J. This is an open-access article distributed under the terms of the Creative Commons Attribution License, which permits unrestricted use, distribution, and reproduction in any medium, provided the original author and source are credited. 